\title{
Pathologic Evaluation of Breast Cancer after Neoadjuvant Therapy
}

\author{
Cheol Keun Park · Woo-Hee Jung \\ Ja Seung Koo \\ Department of Pathology, Yonsei University \\ College of Medicine, Seoul, Korea \\ Received: January 5, 2016 \\ Revised: February 1, 2016 \\ Accepted: February 2, 2016 \\ Corresponding Author \\ Ja Seung Koo, MD \\ Department of Pathology, Severance Hospital, \\ Yonsei University College of Medicine, \\ 50-1 Yonsei-ro, Seodaemun-gu, Seoul 03722, \\ Korea \\ Tel: +82-2-2228-1772 \\ Fax: +82-2-362-0860 \\ E-mail: kjs1976@yuhs.ac
}

Breast cancer, one of the most common cancers in women, has various treatment modalities. Neoadjuvant therapy (NAT) has been used in many clinical trials because it is easy to evaluate the treatment response to therapeutic agents in a short time period; consequently, NAT is currently a standard treatment modality for large-sized and locally advanced breast cancers, and its use in early-stage breast cancer is becoming more common. Thus, chances to encounter breast tissue from patients treated with NAT is increasing. However, systems for handling and evaluating such specimens have not been established. Several evaluation systems emphasize a multidisciplinary approach to increase the accuracy of breast cancer assessment. Thus, detailed and systematic evaluation of clinical, radiologic, and pathologic findings is important. In this review, we compare the major problems of each evaluation system and discuss important points for handling and evaluating NAT-treated breast specimens.

Key Words: Breast neoplasms; Neoadjuvant therapy; Pathologic response evaluation
Application of neoadjuvant therapy (NAT) has become a more common breast cancer treatment due to the diversity and rapid development of associated therapeutic agents. NAT is currently established as a standard therapeutic approach for patients with large $(>2 \mathrm{~cm})$ and locally advanced breast cancer. ${ }^{1}$ In addition, trials for NAT use in early-stage breast cancer are gradually increasing. ${ }^{2}$ Although there is no gain in survival benefit from NAT for breast cancer, it does offer several significant advantages over other modalities: (1) Response efficiency to a new therapeutic agent can be assessed ${ }^{3-5}$ because it is easy to detect a treatment response in a relatively short time period. In this respect, many clinical trials have been designed to evaluate NAT. ${ }^{6}$

(2) Patients with large cancers who show a response to NAT can undergo breast-conservation surgery. ${ }^{7.8}$ (3) The degree of response to NAT can play a role as a prognostic factor; one study reported that the rate of local recurrence depends on the extent of residual tumor after NAT. ${ }^{9}$ Given the potential benefits, exact assessment of breast specimens after NAT is very important. However, standard guidelines for pathologic evaluation of breast specimens after NAT have not been established. ${ }^{9-14}$ Herein, we offer a concise review of the various standard guidelines for pathologic assessment of breast cancer specimens after NAT.

\section{EVALUATION OF BREAST CANCER SPECIMENS AFTER NEOADJUVANT THERAPY}

\section{Specimen handling}

Identification of the tumor bed is important for the handling of breast specimens after NAT. Close examination of fresh specimens cut into 5 -mm sections or smaller is required for identification of the tumor bed. However, some cases require extensive sampling because of uncertainty in the gross identification of tumor bed. There have been attempts to insert metallic clips while conducting breast core biopsy for easy recognition of the tumor bed. ${ }^{15-18}$ However, this method cannot locate the tumor bed accurately because the inserted metallic clip shifts over time. ${ }^{19}$ Some guidelines suggest that small specimens $(<5 \mathrm{~cm}$ at the widest diameter or $<30 \mathrm{~g}$ ) should be thinly sectioned and submitted in their entirety so that the specimens can be reintegrated upon histologic evaluation. However, these methods have limitations in that samples for research use cannot be secured. ${ }^{20}$ It is crucial to select representative sections when dealing with large specimens, such as those from a large lumpectomy or mastectomy. The important goal in specimen selection is to identify the area that correlates best with clinical and radiologic findings. This area, which is known as the pretreatment area, should com- 
prise grossly identifiable tumor bed, a metallic clip, and peritumoral tissue..$^{20}$ After slicing surgical specimens into $\leq 5-\mathrm{mm}$ sections, the cross-section that includes the largest pretreatment area should be selected for sampling. The extent of tissue sampling varies according to guidelines: one or two tissue blocks from every $1 \mathrm{~cm}$ of pretreatment tumor ${ }^{13,20}$ or 10 blocks at least from an entire specimen. ${ }^{4}$ Because histologic patterns of residual post-NAT breast cancer tumors are diverse, different sampling methods can yield different evaluation results (Fig. 1), potentially resulting in sampling error. Even so, submission of large surgical samples in their entirety is not recommended because it is inefficient and offers little information despite the intensive sampling effort required. ${ }^{21}$ Thus, the extent of tissue sampling should be optimized and determined on a case-by-case basis considering clinical, macroscopic, and radiologic features. However, it is important, when creating sample specimens, to provide annotations and photographs of each tissue block to clarify the origin of tissue sections; this enables the pathologists conducting evaluations to identify correlations between macroscopic and histologic features. ${ }^{20,21}$ Also, exact descriptions, including the size of any grossly visible tumor beds and distances from resection margins, should be recorded.

\section{Microscopic pathologic report}

Pathologic variables that describe surgical breast cancer specimens that were not exposed to NAT are also important for postNAT specimen. However, several factors should be taken into account, due to the diversity of evaluation systems for post-NAT

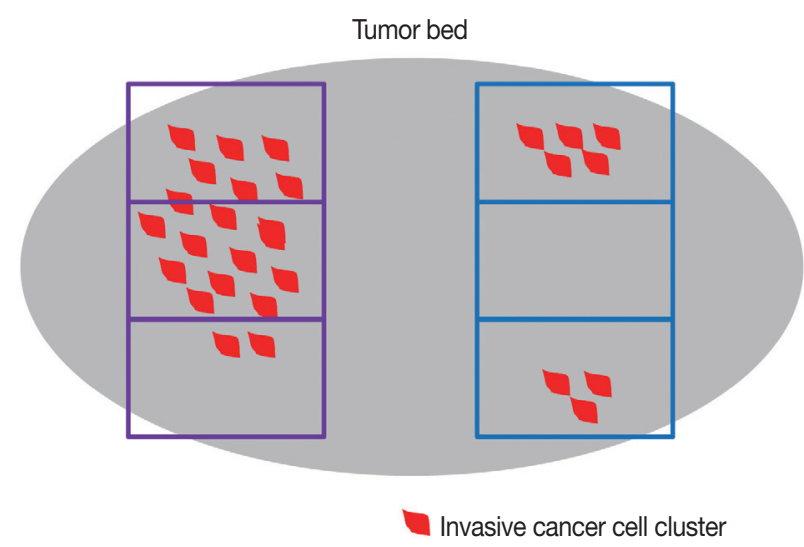

Fig. 1. Differences in tumor evaluation results according to tissue sampling method in breast cancer after neoadjuvant therapy. In this example, when sampling in the area indicated by the blue rectangle, aspects of the residual tumor (e.g., tumor size/extent) are observed and appear different from the sampling area indicated by the purple rectangle, where heterogeneity of the residual tumor and tumor bed is present. breast cancer, including differences in major variables of each evaluation system and histologic factors causing post-NAT changes (Table 1). A summary of the pathologic reports for breast cancer after NAT is provided in Table 2.

\section{Histologic tumor subtype and grade}

In principle, the method to evaluate histologic subtype and tumor grade in breast cancer patients who received NAT is the same as that used for patients with non-neoadjuvant cancer. However, it is necessary to consider that NAT can affect histologic architecture, nuclear features, and tumor mitosis. ${ }^{5,22-24}$ Thus, some cases require comparison with pretreatment biopsy findings.

\section{Tumor size and extent}

There are many potential variables that can be used for assessing tumor size/extent in breast cancer patients who received NAT. Variable relevance depends on which tumor-response evaluation system is being used, because each system offers a different definition of significant tumor size. For example, the largest contiguous focus of the invasive cancer is the most important factor in determining ypT stage in ypTNM system. ${ }^{10}$ Contrarily, the two dimensions of the largest residual area of remaining invasive cancer are most important according to the Residual Cancer Burden (RCB) system. ${ }^{14}$ For the RCB system, however, the residual invasive cancer does not need to be contiguous, leading to a discrepancy in perceived tumor size between the two systems. ${ }^{14}$ The largest discrepancies in tumor size/extent due to the differences in measurement methods were observed when the tissue response pattern after NAT manifested as a scattered pattern (Fig. 2).

\section{Tumor cellularity}

Though NAT can affect several parameters of breast cancer, tumor cellularity is one of the most representative factors. ${ }^{25} \mathrm{Tu}-$ mor cellularity is not always recorded in pathologic reports because it is important in some tumor-response systems ${ }^{11,13,14}$ but not in others. ${ }^{10,12,26}$ There are several factors that should always be considered when evaluating tumor cellularity. The first factor is the comparison of cellularity in pre- and post-treatment specimens (Fig. 3). Differences between pre- and post-treatment cellularity are important for some tumor-response systems; ${ }^{11}$ however, pretreatment cellularity is not considered in the RCB system. ${ }^{14}$ The second factor is tumor heterogeneity. Because residual tumor cellularity can appear heterogeneous after NAT, extensive tissue sampling should be performed. However, the majority of systems do not specifically include the cellularity of 
Table 1. Comparison of pathologic response evaluation system for breast cancer after neoadjuvant therapy

\begin{tabular}{|c|c|c|c|c|}
\hline System & Included variable & Definition of $\mathrm{pCR}$ & Category status & Reference \\
\hline \multirow[t]{4}{*}{$\overline{\operatorname{AJCC}(y)}$} & Size of invasive carcinoma & $\begin{array}{l}\text { No invasive carcinoma } \\
\text { in breast and lymph node }\end{array}$ & Stage 0 & $\begin{array}{l}\text { Boughey } \\
\text { et al. }{ }^{8}\end{array}$ \\
\hline & $\begin{array}{l}\text { Lymph nose status (the number of } \\
\text { metastatic lymph node and size } \\
\text { of metastatic deposit) }\end{array}$ & & Stage 1 & \\
\hline & & & Stage 2 & \\
\hline & & & Stage 3 & \\
\hline \multirow[t]{3}{*}{ B-18 } & Treatment effect in invasive carcinoma & $\begin{array}{l}\text { No invasive carcinoma } \\
\text { in breast and lymph node }\end{array}$ & No pathologic response & $\begin{array}{l}\text { Diaz } \\
\text { et al. }{ }^{24}\end{array}$ \\
\hline & $\begin{array}{l}\text { Lymph nose status (the number of } \\
\text { metastatic lymph node and size } \\
\text { of metastatic deposit) }\end{array}$ & & Pathologic partial response & \\
\hline & & & Pathologic complete response & \\
\hline \multirow[t]{5}{*}{ Miller-Payne } & Presence of invasive carcinoma & $\begin{array}{l}\text { No invasive carcinoma } \\
\text { in breast }\end{array}$ & $\begin{array}{l}\text { Grade 1: no change or some minor alteration in } \\
\text { individual malignant cells, but no reduction in } \\
\text { overall cellularity }\end{array}$ & $\begin{array}{l}\text { Mamounas } \\
\text { et al. }{ }^{9}\end{array}$ \\
\hline & Tumor cellularity & & $\begin{array}{l}\text { Grade 2: a minor loss of tumor cells, but overall } \\
\text { high cellularity; up to } 30 \% \text { reduction of cellularity }\end{array}$ & \\
\hline & & & $\begin{array}{l}\text { Grade 3: between an estimated 30\% and 90\% } \\
\text { reduction in tumor cellularity }\end{array}$ & \\
\hline & & & $\begin{array}{l}\text { Grade 4: a marked disappearance of more than } \\
90 \% \text { of tumor cells such that only small clusters } \\
\text { or widely dispersed individual cells remain }\end{array}$ & \\
\hline & & & $\begin{array}{l}\text { Grade 5: no invasive malignant cells identifiable in } \\
\text { sections from the site of the tumor }\end{array}$ & \\
\hline \multirow[t]{3}{*}{ MNPI } & Size of invasive carcinoma & $\begin{array}{l}\text { No invasive carcinoma } \\
\text { in breast and lymph node }\end{array}$ & $\begin{array}{l}\text { MNPI=0.2xtumor size+lymph node stage+MSBR } \\
\text { grade }\end{array}$ & $\begin{array}{l}\text { Carey } \\
\text { et al. } .^{10}\end{array}$ \\
\hline & Tumor grade & & $\begin{array}{l}\text { Lymph node state: } 1 \text {, node negative; } 2,1-3 \text { positive; } \\
3, \geq 4 \text { positive }\end{array}$ & \\
\hline & $\begin{array}{l}\text { Lymph nose status (the number of } \\
\text { metastatic lymph node) }\end{array}$ & & & \\
\hline \multirow[t]{6}{*}{ Pinder } & Tumor proportion (\%) in remaining breast & $\begin{array}{l}\text { No invasive carcinoma } \\
\text { in breast and lymph node }\end{array}$ & Complete pathologic response & $\begin{array}{l}\text { Ogston } \\
\text { et al. }{ }^{11}\end{array}$ \\
\hline & $\begin{array}{l}\text { Lymph nose status (presence of } \\
\text { evidence of response) }\end{array}$ & & Partial response to therapy & \\
\hline & & & $<10 \%$ of tumor remaining & \\
\hline & & & $10 \%-50 \%$ of tumor remaining & \\
\hline & & & $>50 \%$ of tumor remaining & \\
\hline & & & No evidence of response & \\
\hline \multirow[t]{4}{*}{ RCB } & Size of tumor bed in two dimension & $\begin{array}{l}\text { No invasive carcinoma } \\
\text { in breast and lymph node }\end{array}$ & RCB 0: no residual disease & $\begin{array}{l}\text { Abrial } \\
\text { et al. }{ }^{12}\end{array}$ \\
\hline & Tumor cellularity & & RCB 1: minimal residual disease & \\
\hline & $\begin{array}{l}\text { Lymph node status (the number of } \\
\text { metastatic lymph node and size } \\
\text { of metastatic deposit) }\end{array}$ & & RCB 2: moderate residual disease & \\
\hline & & & RCB 3: extensive residual disease & \\
\hline
\end{tabular}

pCR, pathologic complete response; AJCC, American Joint Committee on Cancer; MNPI, Modified scores from Nottingham Prognostic Index; MSBR grade, Modified Scarff Bloom Richardson grade; RCB, residual cancer burden.

residual heterogeneous tumors, except for the RCB system, which recommends mentioning the average tumor cellularity. ${ }^{14}$

\section{Lymphovascular invasion}

Lymphovascular invasion (LVI) is documented in most pathologic reports because it is a significant prognostic factor in nonneoadjuvant breast cancer. ${ }^{27,28}$ Though there are insufficient data on whether LVI is independently significant in neoadjuvant spec- imens, it should still be mentioned in pathologic reports. ${ }^{20}$ Ductal carcinoma in situ (DCIS) and LVI are defined as resistant breast cancer components after NAT.22 Therefore, in some situations, the only residual after NAT is tumor emboli in lymphovascular space, with no residual tumor in the breast parenchyma (Fig. 4). ${ }^{29}$ According to these guidelines, researchers have recommended that such cases not be regarded as pathologic complete response (pCR). ${ }^{20}$ Consequently, several LVI measurement methods have 
Table 2. Example of pathologic report form in breast cancer after neoadjuvant therapy

\begin{tabular}{|c|}
\hline Pathologic report form \\
\hline Gross finding \\
\hline Residual identified tumor: yes/no \\
\hline Quadrant of tumor \\
\hline Multifocality: yes/no \\
\hline Size of residual tumor: $x x \mathrm{~mm}$ \\
\hline Identified clip of marker: yes/no \\
\hline Microscopic finding \\
\hline Histologic diagnosis: invasive carcinoma, NST \\
\hline Histologic grade: I/I//III (tubule score-nuclear grade-mitosis score) \\
\hline Size of residual tumor bed: $\mathrm{x} \mathrm{mm}$ \\
\hline Size of the largest residual invasive carcinoma: $\mathrm{x}$ mm \\
\hline Residual tumor cellularity: \% \\
\hline Lymphovascular invasion: absent/present \\
\hline DCIS component: yes/no \\
\hline Total tumor size including DCIS: $x$ mm \\
\hline Extensive intraductal component: yes/no \\
\hline Type: cribriform/micropapillary/solid/papillary \\
\hline Nuclear grade: low/intermediate/high \\
\hline Necrosis: absent/present (focal/commedo) \\
\hline ER/PR/HER-2 status: optional \\
\hline Resection margin \\
\hline Invasive carcinoma: absent/present; distance to the closest margin \\
\hline DCIS: absent/present; distance to the closest margin \\
\hline Tumor bed: absent/present \\
\hline Lymph node status \\
\hline Number of sentinel lymph nodes \\
\hline Number of total axillary lymph nodes \\
\hline Number of lymph nodes with macrometastasis \\
\hline Size of largest metastasis: mm \\
\hline Number of lymph nodes with micrometastasis \\
\hline Number of lymph nodes with isolated tumor cells \\
\hline $\begin{array}{l}\text { Number of lymph nodes with histologic evidence of treatment } \\
\text { response but no tumor cells }\end{array}$ \\
\hline Extracapsular extension: yes/no \\
\hline
\end{tabular}

NST, no specific type; DCIS, ductal carcinoma in situ; ER, estrogen receptor; PR, progesterone receptor; HER-2, human epidermal growth factor receptor-2.

been suggested, including measurement according to size $e^{20}$ or using semi-quantitative methods (focal or extensive). ${ }^{30}$

\section{Surgical margins}

Evaluation of resection margins is identical to that for nonneoadjuvant breast cancer specimens. Careful examination is required for evaluation of resection margins in neoadjuvant specimens because grossly invisible residual tumors or multiple scattered microscopic tumor foci are common. Furthermore, when the resection margin involves the tumor bed, it should be documented in the pathological report.

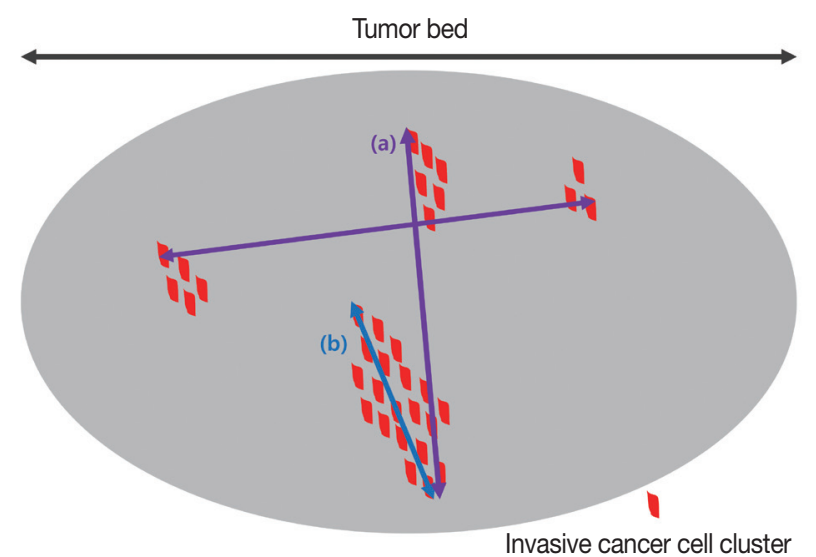

Fig. 2. Comparison of tumor size/extent measurements between the Residual Cancer Burden (RCB) and ypTNM systems. In the RCB system, the largest cross-section among areas with invasive tumors is measured in two dimensions (a). In the ypTNM system, the largest contiguous invasive carcinoma foci are measured (b).

\section{Evaluation of the axillary lymph node after NAT}

The evaluation method for axillary lymph nodes is the same as that for non-neoadjuvant cases. Generally, all lymph nodes are sectioned into 2-mm intervals and sampled in their entirety for microscopic evaluation. Sometimes lymph nodes with complete treatment response are observed under microscopic evaluation for characteristic features, such as fibrous scarring, lymphocytic depletion, or histiocytic aggregation, without any identifiable tumor cell clusters (Fig. 5). If lymph nodes with these features are identified during microscopic evaluation, the total number observed should be noted in the pathologic report. ${ }^{31}$ When metastatic deposits are observed, the size of the largest metastatic tumor and presence/absence of extranodal extension should be recorded. It is difficult to measure the size of the largest metastatic tumor when the treatment response is accompanied by metastasis. In cases with multiple singly scattered tumor cells that involve the entire lymph node and when the treatment response is not accompanied by fibrosis, the size of the metastatic tumor is determined by measuring the size of the largest cell cluster. Some guidelines recommend measuring the sizes of the tumor cells and intervening stroma - not the largest cell cluster-when accompanied by a tumor response; consensus for these measurements has not been established among the various evaluation systems. ${ }^{20}$ Thus, when metastatic deposits are observed during microscopic evaluation, conditions such as macrometastasis, micrometastasis, and isolated tumor cells can be altered by changes in the sizes of metastatic deposits according to applied systems. However, residual disease in the lymph nodes are not considered pCR in most systems. ${ }^{10,20}$ 

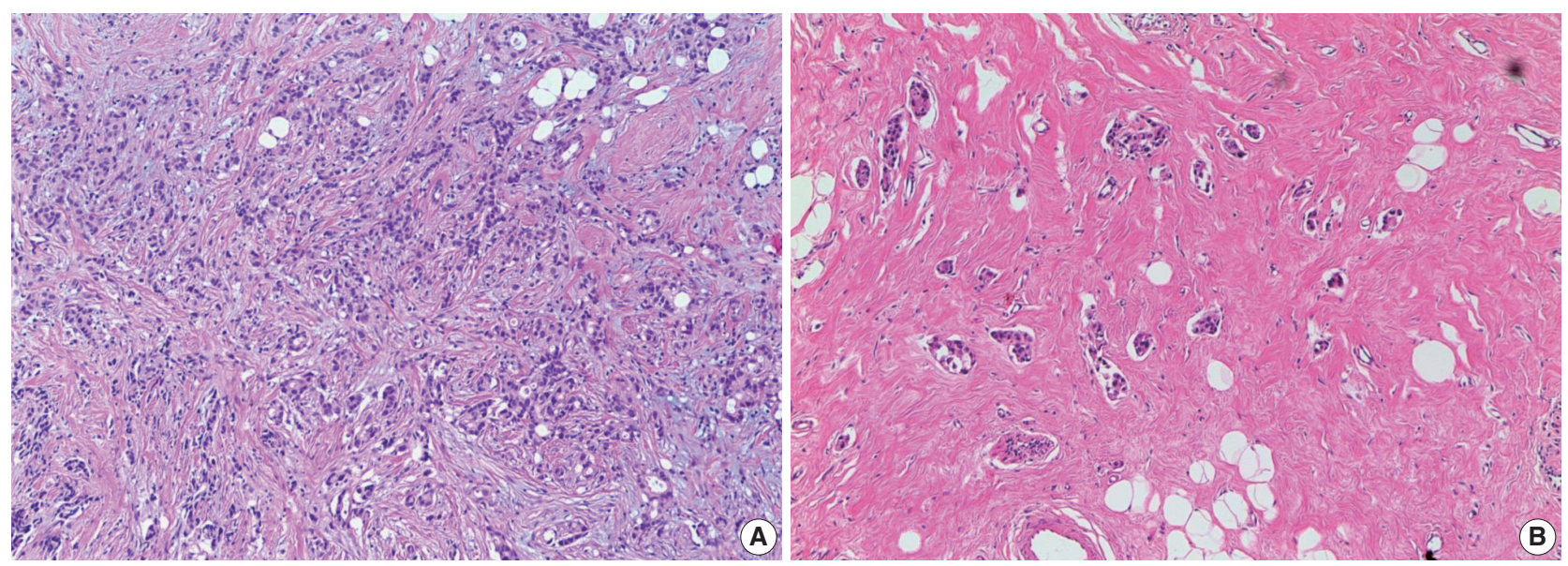

Fig. 3. Comparison of tumor cellularity between pre-neoadjuvant therapy (NAT) and post-NAT. In comparison with the tumor cellularity of a pre-NAT biopsy (A), the tumor cellularity observed in a post-NAT surgical specimen (B) is significantly low.
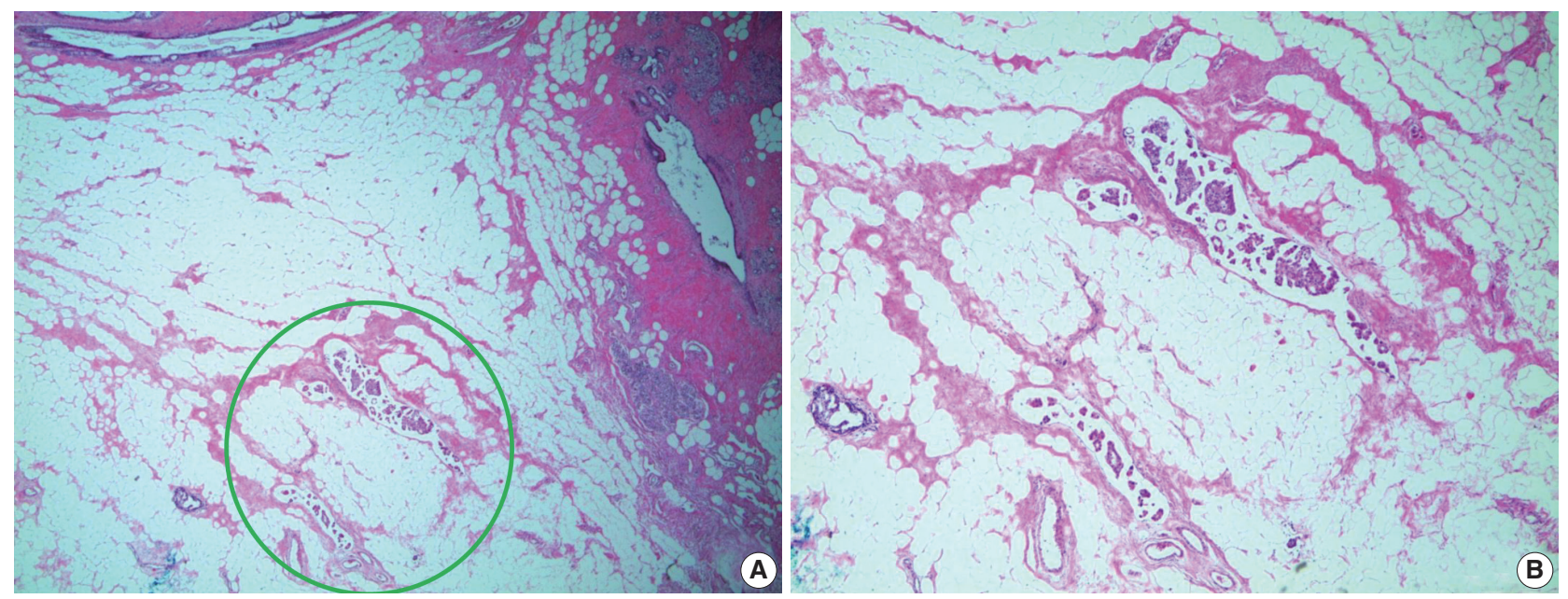

Fig. 4. Residual tumor emboli in lymphovascular space after neoadjuvant therapy (NAT) (A, B). There are only tumor emboli in the lymphovascular space after NAT.

\section{Pathologic complete response}

Though each system that evaluates treatment responses to NAT has a unique definition of $\mathrm{pCR}$, all systems record whether the patient has invasive carcinoma and whether it is identified in the breast parenchyma. ${ }^{9-14}$ Significant differences among these evaluation systems are based on the inclusion or exclusion of DCIS and axillary lymph node status. Thus, description of DCIS and axillary lymph node status should always be included in pathologic reports because the treatment response evaluation systems differ across institutions.

\section{Re-evaluation of biomarkers in breast cancer after NAT}

Estrogen receptor (ER), progesterone receptor (PR), and human epidermal growth factor receptor-2 (HER-2), which are representative biomarkers of breast cancer, should be used for eval- uating invasive breast cancer; however, there is no consensus on whether ER, PR, and HER-2 status should be re-evaluated in breast cancer patients who received NAT. Different guidelines suggest different processes based on core biopsy results, because ER, PR, and HER-2 statuses after NAT are evaluated based on the biomarker status of pretreatment core biopsy. If ER, PR, and HER-2 statuses from pre-treatment core biopsy are all positive, there will be no changes in status for most patients; thus, reevaluation is generally not recommended. However, re-evaluation is considered necessary in the following circumstances: (1) negative or equivocal results in core biopsy, (2) only DCIS or insufficient invasive carcinoma in core biopsy, (3) core biopsy performed at another institute, and (4) no treatment response. ${ }^{20,21}$ Additionally, re-evaluation should be performed when the patient is enrolled in a clinical trial protocol or when ER, PR, or 

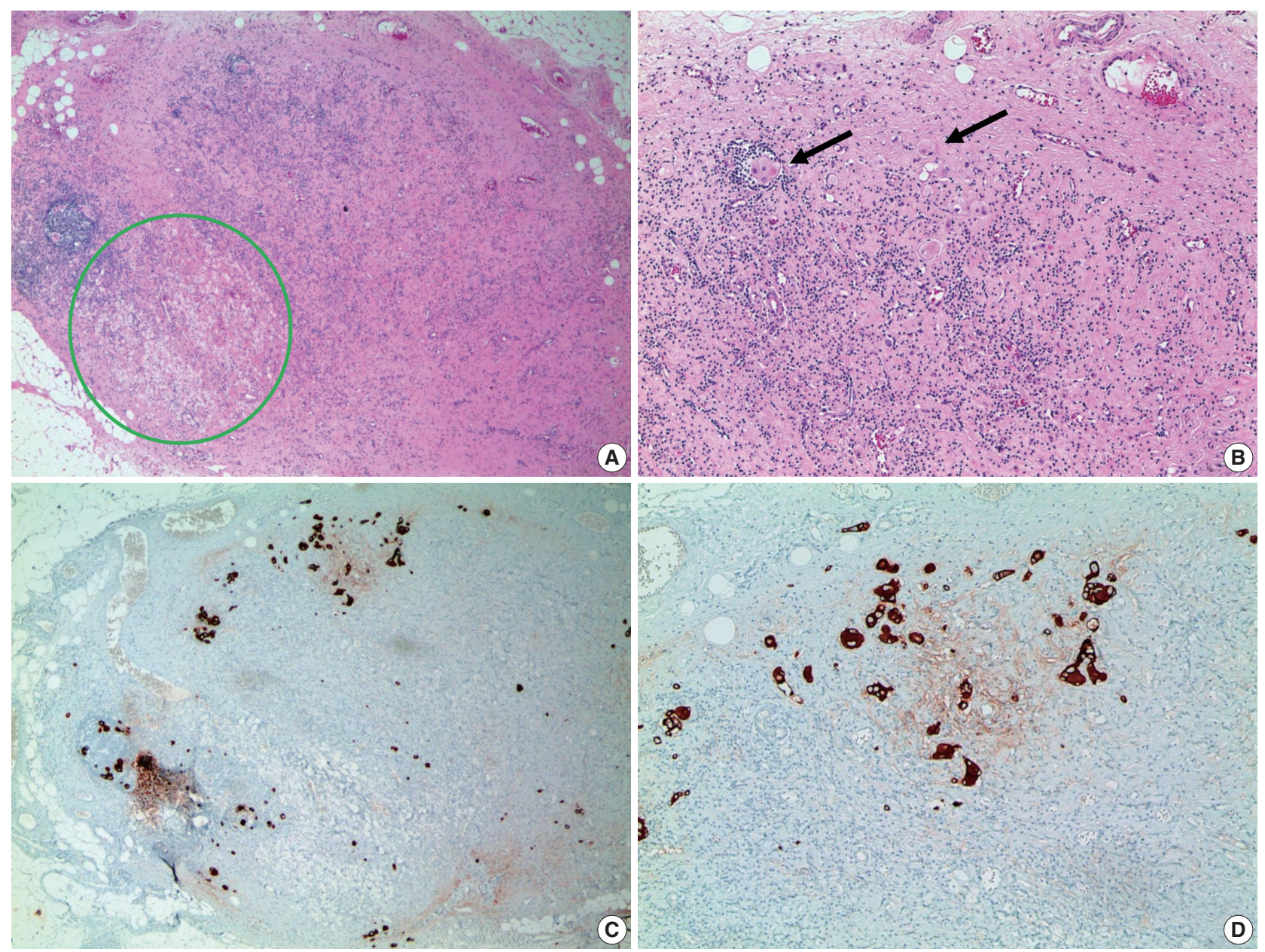

Fig. 5. Metastatic residual carcinoma in a lymph node with histologic features indicative of tumor regression: in low-power view, an axillary lymph node shows lymphocyte depletion, fibrosis, and aggregation of foamy histiocytes (green circle, A), which we suggest are histologic features indicative of tumor regression due to neoadjuvant therapy. In high-power view, metastatic tumor cell clusters are identified in a regressed lymph node (arrows, B). Immunohistochemistry for cytokeratin is helpful to identify metastatic tumor cell clusters in a regressed lymph node (C, D).

HER-2 status is unknown.

\section{CONCLUSIONS}

The number of existing post-NAT breast cancer specimens has recently increased because NAT is now established as an effective treatment approach for patients with large or locally advanced breast cancer and for cases of early-stage breast cancer. However, guidelines for pathologic evaluation of breast cancer after NAT have not been established; instead, there are several evaluation systems, each with different major main-effect variables. Moreover, from macroscopic examination to microscopic evaluation, there are several obstacles to pathologic evaluation of neoadjuvant breast cancer because there is a diverse range of histologic responses to NAT. Pathologic evaluation of residual disease is the most essential component of post-NAT breast cancer evaluation. Thus, the evaluation should be conducted based on close comparisons and correlations between clinical, radiologic, and pathologic findings.

\section{Conflicts of Interest}

No potential conflict of interest relevant to this article was reported.

\section{Acknowledgments}

This study was supported by a grant from the National $R \& D$ Program for Cancer Control, Ministry of Health \& Welfare, Republic of Korea (1420080); the Basic Science Research Program through the National Research Foundation of Korea (NRF); 
and by the Ministry of Science, ICT, and Future Planning (2015R1A1A1A05001209).

\section{REFERENCES}

1. Thompson AM, Moulder-Thompson SL. Neoadjuvant treatment of breast cancer. Ann Oncol 2012; 23 Suppl 10: x231-6.

2. Moreno-Aspitia A. Neoadjuvant therapy in early-stage breast cancer. Crit Rev Oncol Hematol 2012; 82: 187-99.

3. Pierga JY, Mouret E, Laurence V, et al. Prognostic factors for survival after neoadjuvant chemotherapy in operable breast cancer: the role of clinical response. Eur J Cancer 2003; 39: 1089-96.

4. Kuerer HM, Newman LA, Smith TL, et al. Clinical course of breast cancer patients with complete pathologic primary tumor and axillary lymph node response to doxorubicin-based neoadjuvant chemotherapy. J Clin Oncol 1999; 17: 460-9.

5. Fisher B, Bryant J, Wolmark N, et al. Effect of preoperative chemotherapy on the outcome of women with operable breast cancer. J Clin Oncol 1998; 16: 2672-85.

6. Esserman LJ, Woodcock J. Accelerating identification and regulatory approval of investigational cancer drugs. JAMA 2011; 306: 2608-9.

7. Bonadonna G, Veronesi U, Brambilla C, et al. Primary chemotherapy to avoid mastectomy in tumors with diameters of three centimeters or more. J Natl Cancer Inst 1990; 82: 1539-45.

8. Boughey JC, Peintinger F, Meric-Bernstam F, et al. Impact of preoperative versus postoperative chemotherapy on the extent and number of surgical procedures in patients treated in randomized clinical trials for breast cancer. Ann Surg 2006; 244: 464-70.

9. Mamounas EP, Anderson SJ, Dignam JJ, et al. Predictors of locoregional recurrence after neoadjuvant chemotherapy: results from combined analysis of National Surgical Adjuvant Breast and Bowel Project B-18 and B-27. J Clin Oncol 2012; 30: 3960-6.

10. Carey LA, Metzger R, Dees EC, et al. American Joint Committee on Cancer tumor-node-metastasis stage after neoadjuvant chemotherapy and breast cancer outcome. J Natl Cancer Inst 2005; 97: 1137-42.

11. Ogston KN, Miller ID, Payne S, et al. A new histological grading system to assess response of breast cancers to primary chemotherapy: prognostic significance and survival. Breast 2003; 12: 320-7.

12. Abrial SC, Penault-Llorca F, Delva R, et al. High prognostic significance of residual disease after neoadjuvant chemotherapy: a retrospective study in 710 patients with operable breast cancer. Breast Cancer Res Treat 2005; 94: 255-63.

13. Pinder SE, Provenzano E, Earl H, Ellis IO. Laboratory handling and histology reporting of breast specimens from patients who have received neoadjuvant chemotherapy. Histopathology 2007; 50: 409-17.

14. Symmans WF, Peintinger F, Hatzis C, et al. Measurement of residu- al breast cancer burden to predict survival after neoadjuvant chemotherapy. J Clin Oncol 2007; 25: 4414-22.

15. Dash N, Chafin SH, Johnson RR, Contractor FM. Usefulness of tissue marker clips in patients undergoing neoadjuvant chemotherapy for breast cancer. AJR Am J Roentgenol 1999; 173: 911-7.

16. Oh JL, Nguyen G, Whitman GJ, et al. Placement of radiopaque clips for tumor localization in patients undergoing neoadjuvant chemotherapy and breast conservation therapy. Cancer 2007; 110: 2420-7.

17. Schulz-Wendtland R, Heywang-Köbrunner SH, Aichinger U, Krämer S, Wenkel E, Bautz W. Do tissue marker clips after sonographically or stereotactically guided breast biopsy improve follow-up of small breast lesions and localisation of breast cancer after chemotherapy? Rofo 2002; 174: 620-4.

18. Youn I, Choi SH, Kook SH, et al. Ultrasonography-guided surgical clip placement for tumor localization in patients undergoing neoadjuvant chemotherapy for breast cancer. J Breast Cancer 2015; 18: 44-9.

19. Margolin FR, Kaufman L, Denny SR, Jacobs RP, Schrumpf JD. Metallic marker placement after stereotactic core biopsy of breast calcifications: comparison of two clips and deployment techniques. AJR Am J Roentgenol 2003; 181: 1685-90.

20. Provenzano E, Bossuyt V, Viale G, et al. Standardization of pathologic evaluation and reporting of postneoadjuvant specimens in clinical trials of breast cancer: recommendations from an international working group. Mod Pathol 2015; 28: 1185-201.

21. Bossuyt V, Provenzano E, Symmans WF, et al. Recommendations for standardized pathological characterization of residual disease for neoadjuvant clinical trials of breast cancer by the BIG-NABCG collaboration. Ann Oncol 2015; 26: 1280-91.

22. Sharkey FE, Addington SL, Fowler LJ, Page CP, Cruz AB. Effects of preoperative chemotherapy on the morphology of resectable breast carcinoma. Mod Pathol 1996; 9: 893-900.

23. Honkoop AH, Pinedo HM, De Jong JS, et al. Effects of chemotherapy on pathologic and biologic characteristics of locally advanced breast cancer. Am J Clin Pathol 1997; 107: 211-8.

24. Diaz J, Stead L, Shapiro N, et al. Mitotic counts in breast cancer after neoadjuvant systemic chemotherapy and development of metastatic disease. Breast Cancer Res Treat 2013; 138: 91-7.

25. Rajan R, Poniecka A, Smith TL, et al. Change in tumor cellularity of breast carcinoma after neoadjuvant chemotherapy as a variable in the pathologic assessment of response. Cancer 2004; 100: 1365-73.

26. Fisher ER, Wang J, Bryant J, Fisher B, Mamounas E, Wolmark N. Pathobiology of preoperative chemotherapy: findings from the National Surgical Adjuvant Breast and Bowel (NSABP) protocol B-18. Cancer 2002; 95: 681-95.

27. Leitner SP, Swern AS, Weinberger D, Duncan LJ, Hutter RV. Predictors of recurrence for patients with small (one centimeter or less) 
localized breast cancer (T1a,b N0 M0). Cancer 1995; 76: 2266-74.

28. Lee AK, Loda M, Mackarem G, et al. Lymph node negative invasive breast carcinoma 1 centimeter or less in size (T1a,bNOMO): clinicopathologic features and outcome. Cancer 1997; 79: 761-71.

29. Rabban JT, Glidden D, Kwan ML, Chen YY. Pure and predominantly pure intralymphatic breast carcinoma after neoadjuvant chemotherapy: an unusual and adverse pattern of residual disease. Am J Surg Pathol 2009; 33: 256-63.
30. Colleoni M, Rotmensz N, Maisonneuve P, et al. Prognostic role of the extent of peritumoral vascular invasion in operable breast cancer. Ann Oncol 2007; 18: 1632-40.

31. Sahoo S, Lester SC. Pathology of breast carcinomas after neoadjuvant chemotherapy: an overview with recommendations on specimen processing and reporting. Arch Pathol Lab Med 2009; 133: $633-42$. 